Labs., Atul Deodhar Grant/research support from: AbbVie, Eli Lilly, GSK, Novartis, Pfizer, UCB, Consultant of: AbbVie, Amgen, Boehringer Ingelheim, Bristol Myer Squibb (BMS), Eli Lilly, GSK, Janssen, Novartis, Pfizer, UCB, Speakers bureau: AbbVie, Amgen, Boehringer Ingelheim, Bristol Myer Squibb (BMS), Eli Lilly, GSK, Janssen, Novartis, Pfizer, UCB, Désirée van der Heijde Consultant of: AbbVie, Amgen, Astellas, AstraZeneca, BMS, Boehringer Ingelheim, Celgene, Cyxone, Daiichi, Eisai, Eli-Lilly, Galapagos, Gilead Sciences, Inc., Glaxo-SmithKline, Janssen, Merck, Novartis, Pfizer, Regeneron, Roche, Sanofi, Takeda, UCB Pharma; Director of Imaging Rheumatology BV

DOI: 10.1136/annrheumdis-2020-eular.474

\section{OP0055 MINIMAL RADIOGRAPHIC DAMAGE OF SACROILIAC JOINTS DETECTED IN PSORIATIC ARTHRITIS PATIENTS}

M. De Hooge ${ }^{1,2}$, A. Ishchenko ${ }^{3}$, S. Steinfeld ${ }^{4}$, A. Nzeusseu Toukap ${ }^{5}$,

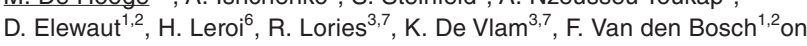
behalf of the BEPAS Study Group. ${ }^{1}$ Ghent University Hospital, Ghent, Belgium; ${ }^{2}$ VIB Ghent University, Ghent, Belgium; ${ }^{3}$ University Hospitals Leuven, Leuven, Belgium; ${ }^{4}$ Clinique St Jean, Brussels, Belgium; ${ }^{5}$ UCLouvain, Brussels, Belgium; ${ }^{6}$ MSD Belgium, Brussels, Belgium; ${ }^{7}$ KU Leuven, Leuven, Belgium

Background: Psoriatic arthritis (PsA) is an inflammatory joint disease that is traditionally included in the Spondyloarthritis (SpA) spectrum. Prevalence and impact of axial involvement in PsA remains understudied but increasingly affects treatment decisions.

Objectives: The first step, in this multi-purpose radiographic study, is to report on baseline radiographic damage of the sacroiliac joints (SIJ) in PsA patients from a prospective multicentre cohort study in private and academic rheumatology practices.

Methods: Data from the Belgian Epidemiological Psoriatic Arthritis Study (BEPAS), a prospective multicentre cohort involving 17 Belgian rheumatology practices. Recruitment was from December 2012 until July 2014. Patients were included in the study when the local rheumatologist could diagnose an existing or new PsA and when patients fulfilled the Classification criteria for Psoriatic Arthritis (CASPAR). Radiographs of the SIJ were obtained at baseline and after 2 years. Two calibrated readers assessed radiographic damage by grading the SIJ according to the modified New York (mNY) criteria. When assessing the images, readers were blinded for clinical data and information from other obtained images (radiographs of the hands, feet and spine). Individual scores as well as consensus scores are described.

Results: In total 461 patients where included in BEPAS. Mean age was $52.79 \pm 12.29$ years and $43.0 \%(n=198)$ were female; average disease duration was $8.5 \pm 9.3 \mathrm{yrs}$ and approximately $34 \%$ of the patients report inflammatory axial pain. From 338 patients SIJ radiographs were obtained. At baseline, the vast majority of patients did not fulfil the $\mathrm{mNY}$ criteria $(n=325,96.2 \%)$, according to both readers. In 8 cases $(2.4 \%)$ there was concordance on fulfilment of the $\mathrm{mNY}$ criteria. Discordant cases $(n=5,1.4 \%)$ were equally distributed. Agreement between the 2 readers was good with $98.5 \%$ overall agreement and kappa $=0.75$. Therefore, with a more sensitive approach (any of the 2 readers scores $\mathrm{mNY}$ positive) we see slight differences; 13 patients $(3.8 \%)$ fulfil the $\mathrm{mNY}$ criteria. Table 1 shows radiographic damage by individual readers

Table. Baseline data on radiographic damage of the sacroiliac joints in Belgian patients with newly diagnosed or existing PsA included in the BEPAS.

\begin{tabular}{clcccc}
\hline $\mathrm{N}=338$ & \multicolumn{2}{c}{ Right sacroiliac joint } & \multicolumn{2}{c}{ Left sacroiliac joint } \\
\hline Grades & Type of lesion & Reader 1 & Reader 2 & Reader 1 & Reader 2 \\
0 & No abnormalities & $298(88.2 \%)$ & $301(89.1 \%)$ & $298(88.2 \%)$ & $296(87.6 \%)$ \\
1 & Indefinite abnormalities & $32(9.5 \%)$ & $23(6.8 \%)$ & $27(8.0 \%)$ & $23(6.8 \%)$ \\
$2-3$ & Abnormalities & $5(1.5 \%)$ & $12(3.6 \%)$ & $9(2.7 \%)$ & $19(5.6 \%)$ \\
& Erosion & $3(0.9 \%)$ & $11(3.3 \%)$ & $4(1.2 \%)$ & $18(5.3 \%)$ \\
& Sclerosis & $4(1.2 \%)$ & $12(3.6 \%)$ & $5(1.5 \%)$ & $13(3.9 \%)$ \\
& Joint space alteration & $1(0.3 \%)$ & $1(0.3 \%)$ & $4(1.2 \%)$ & $2(0.6 \%)$ \\
& (narrowing or widening) & & & & \\
\multirow{2}{*}{4} & Partial ankylosis & $2(0.6 \%)$ & $3(0.9 \%)$ & $5(1.5 \%)$ & $8(2.4 \%)$ \\
& Total ankylosis & $3(0.9 \%)$ & $2(0.6 \%)$ & $4(1.2 \%)$ & - \\
\hline
\end{tabular}

In 128 patients (37.9\%) a follow-up x-ray after 2 years was available. In 124 patients $(96.9 \%)$ there was reader agreement on $\mathrm{mNY}$ negative status. There was disagreement between readers on a positive $\mathrm{mNY}$ in 2 patients (equally distributed) and agreement on 2 patients (1.6\%). There were no patients with consensus between readers on the change in mNY over 2 years, but 1 reader reported 1 patient becoming $\mathrm{mNY}$ positive after 2 years.
Conclusion: Despite the patient self-identified presence of axial disease in up to $34 \%$ in this cohort of PsA patients, there was minimal radiographic damage on SIJ, suggesting that SIJ disease is not a major manifestation of PSA.

Disclosure of Interests: Manouk de Hooge: None declared, Alla Ishchenko: None declared, Serge Steinfeld: None declared, Adrien Nzeusseu Toukap Grant/research support from: AbbVie, Celgene Corporation, Janssen, Pfizer, UCB - grant/research support, Consultant of: AbbVie, Eli Lilly, Janssen Novartis, UCB - consultant, Speakers bureau: AbbVie, Eli Lilly, Janssen, Novartis, UCB - advisory board member, Dirk Elewaut: None declared, Hermine Leroi Employee of: MSD Belgium, Rik Lories Grant/research support from: AbbVie, Boehringer Ingelheim, Celgene Corporation, Eli Lilly, Galapagos, Janssen, MSD, Novartis, Pfizer, Samumed and UCB - grant/research support (on behalf of Leuven Research and Development), Consultant of: AbbVie, Boehringer Ingelheim, Celgene Corporation, Eli Lilly, Galapagos, Janssen, MSD, Novartis, Pfizer, Samumed and UCB - consultant (on behalf of Leuven Research and Development), Speakers bureau: AbbVie, Boehringer Ingelheim, Celgene Corporation, Eli Lilly, Galapagos, Janssen, MSD, Novartis, Pfizer, Samumed and UCB - speaker (on behalf of Leuven Research and Development), Kurt de Vlam Grant/research support from: Celgene, Eli Lilly, Pfizer Inc, Consultant of: AbbVie, Eli Lilly, Galapagos, Johnson \& Johnson, Novartis, Pfizer Inc, UCB, Filip van den Bosch Consultant of: AbbVie, Celgene Corporation, Eli Lilly, Galapagos, Janssen, Novartis, Pfizer, and UCB, Speakers bureau: AbbVie, Celgene Corporation, Eli Lilly, Galapagos, Janssen, Novartis, Pfizer, and UCB

DOI: 10.1136/annrheumdis-2020-eular.2392

\section{OP0056 PERSISTENCE OF BIOLOGIC TREATMENT IN PSORIATIC ARTHRITIS: A POPULATION-BASED STUDY IN SWEDEN}

K. Geale $^{1,2}$, I. Lindberg ${ }^{1}$, E. Paulsson ${ }^{1}$, C. Wennerström ${ }^{3,4}$, A. Tjärnlund ${ }^{3}$, V. Taliadouros ${ }^{3}$, W. Noel ${ }^{3}$, D. Enkusson ${ }^{3}$, E. Theander ${ }^{3}$, S. Bruce Wirta ${ }^{3}$. ${ }^{1}$ Quantify Research AB, Stockholm, Sweden; ${ }^{2}$ Public Health and Clinical Medicine, Umeå University, Umeå, Sweden; ${ }^{3}$ Janssen Pharmaceutica NV, Sweden, Belgium; ${ }^{4}$ Department of Epidemiology Research, Statens Serum Institut, Copenhagen, Denmark

Background: Psoriatic arthritis (PsA) is a chronic, heterogeneous, immune-mediated seronegative arthritis characterized by joint inflammation in people with skin psoriasis ( $\mathrm{PsO}$ ). In recent years several effective biologic treatments such as tumour necrosis factor inhibitors (TNFi), interleukin (IL) 12 and 23 inhibitors (IL-12/23i), and IL 17 inhibitors (IL-17i) have been introduced for PsA. Discontinuation (non-persistence) of therapy is usually a consequence of lack of effect and intolerability.

Objectives: Compare time to discontinuation of TNFi (adalimumab, ADA), IL-17i (secukinumab, SEC), and IL-12/23i (ustekinumab, UST) treatment exposures and the association with previous biologic treatment experience.

Methods: Population-based national health data from the Swedish Patient Registry, Prescribed Drug Registry and Cause of Death Registry were linked at the patient level and used to identify treatment exposures in PsA patients initiating ADA, SEC, or UST between January 2008 and September 2018. Discontinuation was defined as a treatment switch to any other PsA-indicated biologic, or failure to re-dispense treatment within a grace period following end of drug supplied. The grace period, defined as the number of days between end of drug supply and re-dispensation during which a patient is considered to be on active treatment, was set dynamically to the number of days of drug supplied in the primary analysis. As a sensitivity analysis, a fixed 90-day grace period was used. Supply was calculated as total milligrams dispensed divided by maintenance dose posology, where the following assumptions were made due to the limitations of the administrative data used: UST patients' weight corresponded to the amount of drug dispensed (both $45 \mathrm{mg}$ and $90 \mathrm{mg}$ dispensations last 84 days), SEC patients with prior TNFi experience consumed $300 \mathrm{mg} / 28$ days and all others consumed $150 \mathrm{mg} / 28$ days, and ADA patients consumed $40 \mathrm{mg} / 14$ days. Adjusted hazard ratios (HR) for time to discontinuation were calculated using a Cox proportional hazards model. Covariates for age, marital status, and previous biologic treatment experience were assessed at the initiation of treatment exposure, while comorbidity including skin $\mathrm{PsO}$ was assessed during the two years prior. Exposures without discontinuation events were censored at death or end of follow-up. The study was approved by the Stockholm Regional Ethical Review Board.

Results: 3,620 discontinuation events were observed in the main analysis across 4,649 treatment exposures (ADA: 3,255; SEC: 887; UST: 507) (Figure 1 unadjusted). 3,162 events were observed in the sensitivity analysis. Average age at treatment initiation was $50,54 \%$ were female, $47 \%$ were biologic treatment naïve, and $39 \%$ had skin PsO. In the multivariate main analysis, UST exhibited lower discontinuation rates vs $\mathrm{ADA}(\mathrm{HR}=0.56,95 \% \mathrm{Cl}$ : $0.49-0.64)$ while there 
was no significant difference between SEC and ADA (HR=1.01, 95\% Cl: $0.88-$ 1.15). In the multivariate sensitivity analysis, both UST (HR=0.81, 95\% Cl: $0.70-$ $0.94)$ and SEC (HR=0.82, 95\% Cl: 0.70-0.95) were associated with significantly lower discontinuation rates ratio relative to ADA. Overall, patients with more biologic treatment experience were statistically significantly $(p<0.05)$ associated with higher risk of treatment discontinuation.

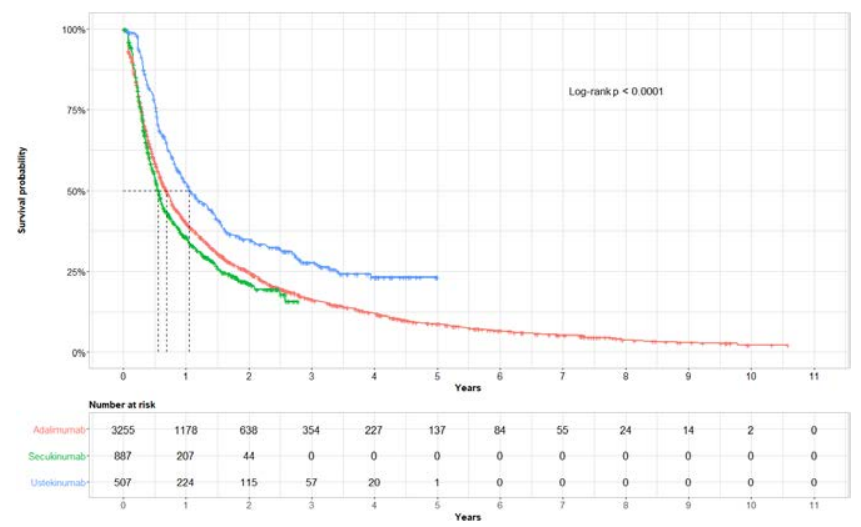

Figure 1. Unadjusted Kaplan-Meier curves of time to treatment discontinuation (main analysis, dynamic grace period)

Conclusion: UST exhibits a favourable treatment persistency profile relative to $A D A$, regardless of the grace period definition. The relative risk of discontinuing SEC vs ADA is sensitive to the grace period. Treatment discontinuation was higher in treatment exposures with more biologic experience.

Disclosure of Interests: Kirk Geale Consultant of: Quantify Research, Speakers bureau: Indirectly as a consultant, Ingrid Lindberg Consultant of: Quantify Research, Emma Paulsson Consultant of: Quantify Research, Christina Wennerström Employee of: Janssen-Cilag Sweden AB, Anna Tjärnlund Employee of: Janssen-Cilag Sweden AB, Virginia Taliadouros Shareholder of: JnJ, Employee of: Janssen Pharmaceuticals NV, Wim Noel Employee of: Janssen Pharmaceuticals NV, Dana Enkusson Employee of: Janssen-Cilag AB, Elke Theander Employee of: Janssen-Cilag Sweden AB, Sara Bruce Wirta Employee of: Janssen-Cilag Sweden AB

DOI: 10.1136/annrheumdis-2020-eular.390

\section{OP0057 SEX SPECIFIC DIFFERENCES IN EARLY PSORIATIC ARTHRITIS}

E. Passia ${ }^{1}$, M. Vis ${ }^{1}$, L. C. Coates ${ }^{2}$, A. Soni ${ }^{2}$, I. Tchetverikov ${ }^{1}$, A. Gerards ${ }^{1}$, L. A. Korswagen ${ }^{1}$, M. R. Kok ${ }^{1}$, W. Van der Graaff ${ }^{1}$, J. Veris-van Dieren ${ }^{1}$, N. Denissen ${ }^{1}$, F. Fodili ${ }^{1}$, M. Starmans ${ }^{1}$, Y. Goekoop-Ruiterman ${ }^{1}$, M. Van Oosterhout ${ }^{1}$, J. Luime ${ }^{1} .{ }^{1}$ CICERO Foundation, Rotterdam, Netherlands; ${ }^{2}$ NDORMS, Uni of Oxford, Oxford, United Kingdom

Background: Although the prevalence of Psoriatic Arthritis (PsA) is the same in men and women, women experience a higher burden of disease (pain, disability, fatigue) (1).The persistent belief that women tend to over-report their symptoms compared to men may also contribute to under or delayed diagnosis in women. The clinical pattern of PsA also differs, with men presenting more commonly with peripheral and axial joint damage and women being affected more frequently by polyarthritis (2). Furthermore, most disease activity measures contain pain and quality of life measurement metrics that may perform differently by sex. As a result, this may affect the clinician's perception of disease severity, influence management decisions and subsequently introduce sex bias in prescribing.

Objectives: To assess sex-related differences in baseline demographics, disease characteristics and evolution over 1 year in patients with newly diagnosed PsA.

Methods: Our study is embedded in the Dutch south-west Early Psoriatic Arthritis prospective cohort study. We described patient characteristics using simple descriptive analysis techniques. For the comparison across sexes and baseline and 1 year follow up, appropriate tests depending on the distribution were used. Results: 273 men and 294 women with no significant differences in age and ethnicity were included. Women reported significantly longer duration of symptoms before diagnosis and significantly fewer of them were in paid employment at baseline. Oligoarthritis was the most common pattern of arthritis in both sexes. Polyarthritis and enthesitis were more prevalent in women who also presented at baseline a significantly higher tender joint count (Fig.1) than men but no difference in swollen joint count.

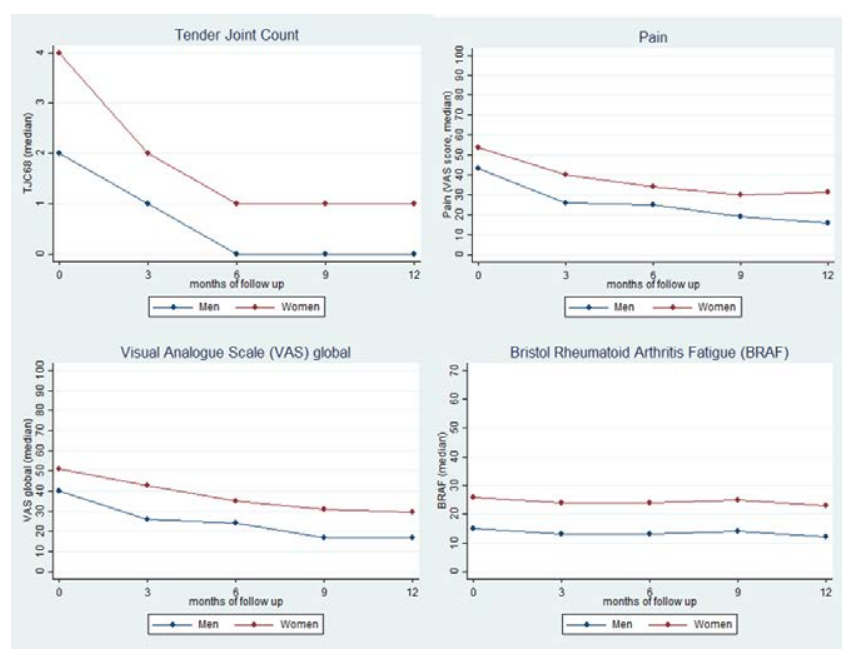

Figure 1. Longitudinal evolution of TJC68, Pain, VAS global, BRAF for men and women in the first year of PsA.

All composite indices (CPDAI, DAPSA, GRACE, MDA, Psoriatic ArthritiS Disease Activity Score) showed significantly worse results in women at baseline Women also suffered more frequently from comorbid medical conditions, fatigue and anxiety, and reported more severe limitations in function and worse quality of life.

At 12 months women, despite the improvement they made, reported significantly higher levels of pain compared to men. Although MDA rates increase over time for both sexes,(Fig.2), it remained significantly more prevalent among men (19.0\% vs $11.1 \%$ at inclusion, $p<0.05$, and $58.1 \%$ vs $35.7 \%, p<0.00$, at T12). DAPSA was significantly higher in women at both timepoints and a significantly higher percentage of men presented remission according to DAPSA score at 12 months.

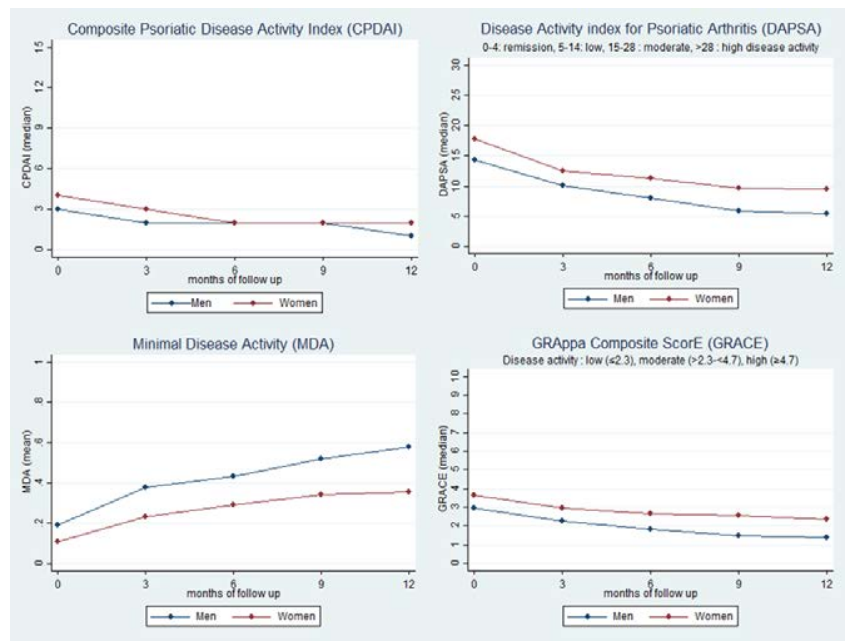

Figure 2. Longitudinal evolution of composite measures for men and women in the first yea of PsA.

Conclusion: After 1 year of follow-up women didn't surpass their baseline disadvantages and despite the improvement, they still present higher disease activity, more pain and lower functional capacity than men. The nature of these findings may advocate a need for sex specific adjustment of treatment strategies and evaluation in psoriatic arthritis as sex-related difference in outcome persisted over time.

\section{References:}

[1] Eder L, Thavaneswaran A, Chandran V, Gladman DD. Gender difference in disease expression, radiographic damage and disability among patients with psoriatic arthritis. Annals of the rheumatic diseases. 2013;72(4):578-82.

[2] Orbai AM, Perin J, Gorlier C, Coates LC, Kiltz U, Leung YY, et al. Determinants of Patient-Reported Psoriatic Arthritis Impact of Disease: An Analysis of the Association with Gender in 458 Patients from 14 Countries. Arthritis care \& research. 2019. 